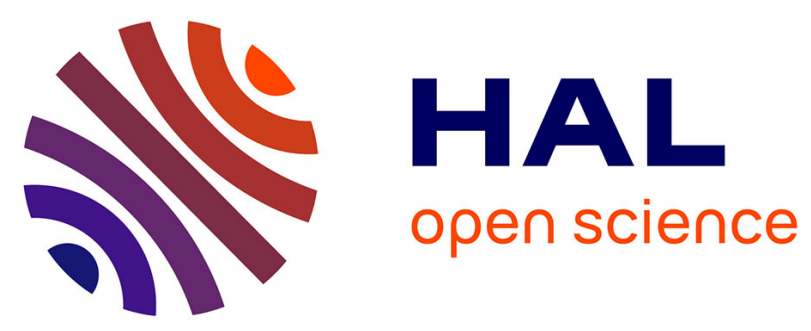

\title{
Association between familiarity disorders and serious violence among inmates with schizophrenia.
}

\author{
Mathilde Horn, Fabien d'Hondt, Axelle Gharib, Laura Gangloff, Alexandre
}

Dumais, Ali Amad, Pierre Thomas, Thomas Fovet, D. Pins

\section{- To cite this version:}

Mathilde Horn, Fabien d'Hondt, Axelle Gharib, Laura Gangloff, Alexandre Dumais, et al.. Association between familiarity disorders and serious violence among inmates with schizophrenia.. Schizophrenia Research, 2018, Schizophrenia Research, 193, pp.447-448. 10.1016/j.schres.2017.06.031 . hal$02358569 \mathrm{v} 2$

\section{HAL Id: hal-02358569 \\ https://hal.univ-lille.fr/hal-02358569v2}

Submitted on 17 May 2021

HAL is a multi-disciplinary open access archive for the deposit and dissemination of scientific research documents, whether they are published or not. The documents may come from teaching and research institutions in France or abroad, or from public or private research centers.
L'archive ouverte pluridisciplinaire HAL, est destinée au dépôt et à la diffusion de documents scientifiques de niveau recherche, publiés ou non, émanant des établissements d'enseignement et de recherche français ou étrangers, des laboratoires publics ou privés. 


\title{
Association between familiarity disorders and serious violence among inmates with schizophrenia
}

\author{
Schizophrenia Research \\ Volume 193, March 2018, Pages 447-448
}

Mathilde Horn ${ }^{1,2, *}$, Fabien D'Hondt $^{1,2}$, Axelle Gharib $^{2}$, Laura Gangloff ${ }^{2}$, Alexandre Dumais $^{3}$, Ali Amad ${ }^{1,2}$, Pierre Thomas ${ }^{1,2}$, Thomas Fovet ${ }^{1,2}$, Delphine Pins ${ }^{1,2}$.

\footnotetext{
${ }^{1}$ Univ. Lille, CNRS, UMR 9193 - SCALab - Sciences Cognitives et Sciences Affectives, F-59000 Lille, France

${ }^{2}$ CHU Lille, Clinique de Psychiatrie, CURE, F-59000 Lille, France

${ }^{3}$ Institut Philippe-Pinel de Montréal, Institut Universitaire en Santé Mentale de Montréal, Université de Montréal, Montréal, Canada

* Corresponding author.

E-mail address: horn.mathilde@gmail.com

Postal address: Centre Hospitalier Universitaire de Lille (CHU Lille), Hôpital Fontan, F-59037 Lille, France
} 
Patients with schizophrenia (SCZ) are at a higher risk of violent behaviour (VB) than members of the general population (Fazel et al., 2009). Nevertheless, many SCZ patients will never exhibit any VB (Large and Nielssen, 2011), and the differences between these individuals and those who commit VB remain unclear. Several authors have drawn attention to delusional misidentification syndromes (DMS), which empirically appear to be more strongly associated with serious violence (Horn et al., 2016; Klein and Hirachan, 2014; Silva et al., 1996).

DMS are specific delusional syndromes in which patients misidentify familiar persons, objects or themselves, holding the delusional belief that they have been replaced or transformed (Carabellese et al., 2014). DMS can, therefore, be considered delusional responses to familiarity disorders, where familiarity is defined as the feeling indicating that a stimulus has been previously encountered (Yonelinas 2001). Interestingly, DMS can be distinguished in hypofamiliarity (e.g., Capgras syndrome) and hyperfamiliarity disorders [e.g., Fregoli syndrome (Klein and Hirachan, 2014)]. The risk of violence of patients with DMS may be dependent upon the type of familiarity disorder. Specifically, severe VB, such as homicide, may be more likely to be observed among SCZ patients with hypofamiliarity disorders because these patients may no longer perceive a person who is a close relative to be a close relative and consider him/her to be a malevolent impostor.

In the current study, we directly examined the association between hypofamiliarity disorders and serious VB in SCZ and a high risk of exhibiting VB, i.e., inmates hospitalized in the Unité Hospitalière Spécialement Aménagée of Lille (a full-time inpatient psychiatric unit for inmates in the North of France). 
Male patients over 18 years of age who had been admitted between January 2016 and December 2016 with a DSM-5 diagnosis of schizophrenia or schizoaffective disorder were included. A retrospective review of their record was conducted to extract the following data: positive psychotic symptoms [(regularly assessed in the unit using the Positive And Negative Severity Scale (PANSS)]; substance use disorders (SUD) and antisocial personality disorder (ASPD) status (according to the DSM-5 criteria); history of violence according to the MacArthur Study of Mental Disorder and Violence criteria, which distinguishes between serious violence, defined as assaults resulting in injury, any use of a weapon, or sexual assault, and other minor forms of violence (Monahan and MacArthur Violence Risk Assessment Study., 2001) and familiarity disorders. Based on a semi-structured interview routinely conducted in the unit, SCZ patients are considered to have a history of hypofamiliarity if they have ever experienced the feeling that a familiar person was similar to a stranger, that something about her/him seemed to be different or that she/he had been replaced by a double (spitting image).

The following two groups of patients were defined according to familiarity disorder status: SCZ patients who had a history of hypofamiliarity disorders $(\mathrm{hF}+)$ and $\mathrm{SCZ}$ patients who did not have a history of such disorders (hF-). Between-group comparisons were performed using chi-square tests for categorical data and independent student's $t$ tests (or Mann-Whitney U tests). Statistical analyses were performed using SPSS.

All 51 patients without missing data (59\% of the initial sample) were included in the study. The results of the analysis are presented in Table 1. Forty-seven percent of patients had a history of hypofamiliarity disorders. No significant between-group differences were identified for age, positive PANSS score, SUD or ASPD status. A significant association 
between hypofamiliarity disorder history and severe VB was observed, with SCZ hF+ prisoners being more likely to present severe VB than SCZ $\mathrm{hF}$ - prisoners $\left(\chi^{2}(1)=5.088, \mathrm{p}=\right.$ $0.024)$.

\section{Table 1}

Age; presence of serious VB, SUD, and ASPD; and PANSS scores by hypofamiliarity status.

\begin{tabular}{lccc}
\hline \multicolumn{1}{c}{ Variable } & $\begin{array}{c}\text { Hypo-familiarity }+ \\
(\mathrm{n}=24)\end{array}$ & $\begin{array}{c}\text { Hypo-familiarity - } \\
(\mathrm{n}=27)\end{array}$ & Group comparison \\
& $33.7( \pm 8.4)$ & $32.0( \pm 10.5)$ & $U=317.000, p=0.741$ \\
Age (years) & $\mathbf{8 7 \%}$ & $\mathbf{5 9 \%}$ & $\chi^{2}(\mathbf{1})=\mathbf{5 . 0 8 8 , p = 0 . 0 2 4}$ \\
Serious VB & $91 \%$ & $81 \%$ & $\chi^{2}(1)=1.113, p=0.291$ \\
SUD & $45 \%$ & $36 \%$ & $\chi^{2}(1)=0.490, p=0.484$ \\
ASPD & $19.2( \pm 6.8)$ & $20.8( \pm 5.4)$ & $U=267.500, p=0.290$ \\
Positive PANSS score & (SUD: substance abuse disorder; ASPD: antisocial personality disorder; VB: violent \\
(Sehavior). Significant differences between groups are indicated in bold.
\end{tabular}

Our results support the hypothesis that prisoners with both schizophrenia and a history of hypofamiliarity disorders are at high risk of severe VB, whereas other risk factors of VB (SUD, ASPD and positive symptoms) were not more frequently identified in the group of $\mathrm{SCZ} \mathrm{hF}+$ than in the group of SCZ hF-. While our results are in line with case studies reporting severe VB among patients with Capgras syndrome (e.g., Bourget and Whitehurst, 2004; Carabellese et al., 2014; Klein and Hirachan, 2014; Silva et al., 1996), this study is, to the best of our knowledge, the first to directly demonstrate an association between hypofamiliarity disorders and serious VB in SCZ. 


\section{References}

Bourget, D., Whitehurst, L., 2004. Capgras syndrome: a review of the neurophysiological correlates and presenting clinical features in cases involving physical violence. Can. J. Psychiatry. 49, 719-25. doi:10.1177/070674370404901102

Carabellese, F., Rocca, G., Candelli, C., Catanesi, R., 2014. Mental illness, violence and delusional misidentifications: The role of Capgras' syndrome in matricide. J. Forensic Leg. Med. 21, 9-13. doi:10.1016/j.jflm.2013.10.012

Fazel, S., Gulati, G., Linsell, L., Geddes, J.R., Grann, M., 2009a. Schizophrenia and Violence: Systematic Review and Meta-Analysis. PLoS Med. 6, e1000120. doi:10.1371/journal.pmed.1000120

Horn, M., Thomas, P., Pins, D., 2016. Preventing violence in schizophrenia: Why do delusional familiarity disorders remain so unfamiliar? Aust. New Zeal. J. Psychiatry 50, 1209-1209. doi:10.1177/0004867416649442

Klein, C.A., Hirachan, S., 2014. The masks of identities: who's who? Delusional misidentification syndromes. J. Am. Acad. Psychiatry Law 42, 369-78.

Large, M.M., Nielssen, O., 2011. Violence in first-episode psychosis: A systematic review and meta-analysis. Schizophr. Res. 125, 209-220. doi:10.1016/j.schres.2010.11.026

Monahan, J., MacArthur Violence Risk Assessment Study., 2001. Rethinking risk assessment: the MacArthur study of mental disorder and violence. Oxford University Press.

Silva, J.A., Harry, B.E., Leong, G.B., Weinstock, R., 1996. Dangerous delusional misidentification and homicide. J. Forensic Sci. 41, 641-4.

Yonelinas, A.P., 2001. Components of episodic memory: the contribution of recollection and familiarity. Philos. Trans. R. Soc. Lond. B. Biol. Sci. 356, 1363-1374. doi:10.1098/rstb.2001.0939. 